\title{
Effect of Feedback on eBay Sellers' Business Using Markov Chain
}

\author{
Y. M. Dib'1, N. Roumieh², G. Saab'2, M. Maroun ${ }^{3}$ \\ ${ }^{1}$ Department of Mathematics, Kurah, Lebanon \\ ${ }^{2}$ Department of Economics, Balamand University, Kurah, Lebanon \\ ${ }^{3}$ Department of Mathematics, Notre Dame University, Louaize, Lebanon \\ Email: youssef.dib@balamand.edu.lb, nourroumieh@gmail.com, gretta.saab@balamand.edu.lb, mmaroun@ndu.edu.lb
}

How to cite this paper: Dib, Y.M., Roumieh, N., Saab, G. and Maroun, M. (2019) Effect of Feedback on eBay Sellers' Business Using Markov Chain. Journal of Mathematical Finance, 9, 325-344. https://doi.org/10.4236/jmf.2019.93019

Received: June 19, 2019

Accepted: August 16, 2019

Published: August 19, 2019

Copyright (c) 2019 by author(s) and Scientific Research Publishing Inc. This work is licensed under the Creative Commons Attribution International License (CC BY 4.0).

http://creativecommons.org/licenses/by/4.0/

\begin{abstract}
Effects of price, sold items, negative feedbacks, positive feedbacks, or no feedbacks are studied for online market engines mainly through eBay. Random walk type model is established to measure the duration that sellers with business effected negatively in order to turn it around. This study was based on data from eBay where not only prices play a role in selling items but also the impact factor that buyers depend on in general. This impact factor was studied for five different types of sellers over the same duration selling the same commodity.
\end{abstract}

\section{Keywords}

Rating System, Seller Reputation, eBay, Markov Chain, Stochastic Process

\section{Introduction}

Nowadays loading market engine is open continuous space done through the internet, electronic market. This market went through many trial and error fixing stages to arrive at this point. First, electronic markets have the problem of asymmetric information, where a seller possesses more information than the buyer. Online trade environment such as eBay is ripe with the possibility of large-scale fraud and deceit (Kollock, 1999) [1]. The lack of information between the two parties of a transaction can decrease market efficiency. Furthermore, adverse selection can conduct high quality sellers to leave the market, creating a Lemons Market as demonstrated by Akerlof (1970) [2]. Buyers are not willing to pay the full price of the high quality product because they cannot differentiate those products from lower quality products. Consequently, the sellers of high quality products are incapable to get the full value of their commodities, and decide to abandon the market. Traditional exchanges depend notably on the trust 
generated by repeated interaction between partners (Ba et al., 1999) [3]. However, in electronic markets most transactions occur among partners that have never met.

In order to alleviate the asymmetric information problem, important mechanisms have been represented to allow the systematic distribution of reputational information. These mechanisms accumulate information on the past performance of a seller and then make that information accessible to potential future buyers. Because sellers know that their performance today will influence their capacity to sell in the future, not only with their current buyer but also with unknown buyers, opportunistic performance is restrained. Thus, less reliable sellers are discouraged from entering the marketplace. Reputation mechanism aims to inform buyers about whether potential sellers are reliable. eBay provides a reputation mechanism that allows buyers and sellers to identify and rate each other after every transaction. This rating system reduces the information asymmetry, by telling buyers whether previous consumers were satisfied with the seller. Both traders have the opportunity to rate their level of satisfaction with the transaction; each evaluation consists of a numerical rating $(+1,-1$, or 0$)$, and a text comment. This information is publicly available on eBay. In such situation, a seller's reputation could well reduce information asymmetries, and thus permit the market to function. Furthermore, the reputation system can enhance the level of trust among traders and can contribute in significant welfare gains (Ben-Ner et al., 2003) [4]. Resnick and Zeckhauser (2002) [5] show the value of the online reputation system in reducing the lemon market problem (Akerlof 1970) that would appear if there was no obvious distinction of quality among sellers. Bolton et al. (2003) [6] examine that a reputation system generates substantial developments in transaction efficiency.

Generally, reputation can improve the efficiency of marketplaces in many ways.

Two of the common ones are:

- A seller's feedback profile can help as a signal to customers of how uncertain it is to buy from that specific seller. This enables each customer to choose sellers to trade with, depend on the customer's level of risk aversion (Resnick and Zeckhauser 2002).

- Sellers will aim to evade negative rating, in order to prevent adverse future effects on their sales volume and the sale price (Dewan and Hsu, 2001 [7], Eaton, 2002 [8], Houser and Wooders, 2005 [9], Livingston, 2005 [10], Lucking-Reiley et al., 2007 [11], McDonald and Slawson, 2002 [12], Melnik and Alm, 2002 [13], Resnick and Zeckhauser, 2002).

Several studies tried to analyze these impacts. The study of Resnick and Zeckhauser develops a model representing that past feedback is convenient as a signal expecting future buyer satisfaction. Other papers have shown the sanctioning result by quantifying the influence of a seller's history on the probability that a product will be sold and the sale price obtained. Our analysis indicated how seller path behavior changes as he received negative feedback. In particular, our 
work studied changes in seller sale price and changes in the volume of sale.

This work is based on studying a large panel of sellers. Our study tracks whether sellers continue to sell products, and when they do, whether they receive positive rating, negative rating, or no rating at all. When a seller receives a negative rating, it marks a significant change in a feedback profile. The paper of Resnick and Zeckhauser, found that negative and neutral rating represented only 1 percent of all rating.

Hence, our work contrasts what happens before receiving a negative rating with what happens after receiving it, in order to know the expected time before the seller with a negative feedback run out of business. Seller action, both before and after getting negative rating, is shown in whether and how frequently they buy products. Buyer behavior is reflected in whether the good is being sold. Both traders action are reflected in the rating that buyers leave to sellers. By the way of illustration, a higher probability of negative rating may reflect worse performance by the sellers, or it may represent a higher willingness of customers to report dissatisfaction. Our study is most related in spirit to that in Cabral and Hortacsu (2010) [14] but there are many differences in our approach and different conclusions.

The study is organized as follows. The next section reviews the current literature on eBays reputation mechanism and focuses on findings from studies closely related to our paper. The third section gives a brief description of the setup of eBays reputation system. Section 4 represents the effects of feedback mechanism and a particular attention is paid to negative feedback left for sellers. Section 5 exposes the five different types of seller found on eBay. Section 6 represents and analyses our stochastic model. Section 7 concludes.

\section{Literature Review}

There are many ways in which the impacts of reputation can be observed. Houser and Wooders (2005) consider an auction with two types of sellers: honest and dishonest. The first type always sends the product as described while the dishonest seller may ship a damaged product or the product may have been incorrectly described or the seller may not deliver the product at all. The seller's reputation score, easily visible to each visitor, is the probability that the first type seller is honest. Then they found that the expected utility of any online consumer is an increasing function in the reputation of the seller, and the consumer is willing to pay more, greater is the reputation score of the seller. Several studies produce an identical result (Klein and Leffler, 1981 [15], Shapiro, 1983 [16], Allen, 1984 [17]).

Theoretical models have created a positive relationship between the item sale price and the reputation of the seller (Klein and Leffler, 1981; Allen, 1984; Houser and Wooders, 2005). The evolution of electronic commerce in recent years has produced environment in which the relationship between price, sale and reputation can be verified empirically. Many authors collected online data to test the impact of the sellers reputation on the buyer's willingness to pay 
(McDonald and Slawson, 2000; Houser and Wooders, 2005). A large number of researches in the literature have conducted empirical studies of the eBays feedback system. They focus on the buyers reaction to sellers feedback profile. Most of these studies estimate the effect of a eBays reputation system on the item price and on sales using cross-sectional regressions. Dewan and Hsu (2001), Eaton (2002), Houser and Wooders (2003), Livingston (2002), Lucking-Reiley and al. (2007), McDonald and Slawson (2002), Melnik and Alm (2002), Resnick and Zeckhauser (2002). While, in our empirical tests a panel data is used. Cabral and Hortacsu, assumed that results from panel data are highly significant, while their results from cross-section data, have less statistical significance.

For the majority of these works, reputation mechanism seems to have an impact on auction sale price; however, there is significant dissimilarity among studies on the extent, magnitude and significance of the impact. Here are, in our knowledge, the main related studies to our paper.

An online field experiment conducted by Resnick and al. (2006) [18] tried to measure the impact of feedback system on the auction price. With similar item auctions sold through a new seller identity and regular identity, conclude that the willingness to pay for batches of vintage postcards were $8.1 \%$ higher for the regular seller. McDonald and Slawson (2002) announce that a seller with a positive feedback profile gets a $5 \%$ higher price than a seller with a low feedback profile and receives more bids. In parallel, Dewan and Hsu (2001) conclude that a higher reputation score raises the wining auction price. Ba and Pavlou (2002) [19], based on a lab experiment, splicing distinct seller feedback scores into real auction listings and questioning people to declare how much they are willing to pay more to distinct sellers. They notice that consumers are willing to pay more to sellers who have high feedbacks. Houser and Wooders (2005) studied 95 auctions of Intel Pentium III 500 processors sold on eBay. They notice that a $10 \%$ increase in positive rating raises price by $0.17 \%$ and a $10 \%$ increase in negative rating decreases it by $0.24 \%$. Then they deduce that sellers feedback profile has an economically and statistically significant impact on items price. Using a probit model, Depken and Gregorius (2010) [20], estimated the impact of seller feedback on the Apple iPhone auction final price selling on eBay. One of their findings is that receiving high feedback is positively correlated with winning price and receiving no feedback or negative ones lowers winning price.

Other studies observe the effect of reputation on final prices in eBay auctions, their findings report that there is an impact of reputation on price, but this impact is relatively small. Among these papers, Lucking-Reiley et al. (2007) studied 461 eBay auctions of U.S. collectible pennies, and report that a one percent raises in positive rating yields only $0.03 \%$ increase in the auction price, whereas a one percent raises in negative rating decreases the product price by $0.11 \%$. The authors conclude that the impact of negative reputation is statistically significant at the $5 \%$ level, while positive rating was statistically not significant. In the same line of thinking, Melnik and Alm (2002) used data from the online auction website eBay to estimate the effect of reputation on the price of the commodity. 
Their empirical results find that a seller with a better reputation can anticipate that the buyer will pay a higher price for the product. Despite the fact that reputation indicates a positive, statistically significant effect on the willingness of consumers to pay for the product, its effect tends to be small. In other words, these authors estimate that the effect of a negative rating is significant but minor in magnitude, and the same stands for the effect of the positive feedback.

In Livingston (2005) paper, a theoretical model of bidder behavior guides an investigation study of how bidders react to sellers with high reputations. In order to test the predictions of the model, Livingston studied 861 eBay auctions of Taylor Made Firesole irons. Results report that reputable sellers do receive significant returns than seller with no reputation. Moreover, products of sellers with better reputation are more likely to result in a sale and bidders are more willing to bid on this auction than on item of sellers who have no reputation. Another conclusion of Livingston paper is that sellers are much more rewarded for the first few positive evaluations they receive, while the effect of additional positive evaluation is small. Ryan Mickey (2010) [21] analysis 183 auctions of Apple iPod Touches on eBay to observe the effect of a seller reputation on price. The study shows that a sellers negative feedback affects the auction price. Indeed, negative rating tends to reduce the price that a seller obtains. David Eaton (2008) has estimated the effect of sellers reputation on the probability of sale and the auction price. He gathered 208 auctions of Paul Reed Smith electric guitars sold on eBay. Eaton report that each additional negative rating left by buyers reduced the percentage of a sale by $1 \%$. He does not notice any strong statistically significant correlation between negative reputation and the probability of sale and on price of sold products. Canals-Cerda (2011) [22] used a panel data technique to test the value of a seller feedback. Based on auctions from a group of self-representing artists who sell their own artwork on eBay, the author shows a statistically significant expected impact of a negative feedback on the behavior of traders. Negative rating is associated with a significant decrease in auction price and a decrease in the probability of sale. Similar to Canals-Cerda (2011) paper, Cabral and Hortacsu (2010) based their study on a panel data to test the effect of eBays reputation feedback. The authors create a theoretical model of eBays reputation system and test empirically its validity. They analyze the effect of rating on the increase of the volume of sales, the frequency of future negative rating and sellers's exit. They report that when a seller first gets negative rating, his weekly sales rate decreases from a $5 \%$ to a negative $-8 \%$. They find that negative feedback has a significant effect on market outcomes. Additionally, seller is more likely to go out of the market the lower his reputation is; and that, just before abandoning, sellers get more negative evaluation than their existence average on eBay.

\section{The eBay Reputation System: The Feedback Counting Strategy}

eBay is an online sale platform that permits sellers to sell new and used products 
at a fixed price or by auction. Created in September 1995, eBay is regarded as one of the leading online auction site for the sale of items and services by hundreds of millions of people around the world and hosts millions of auctions every day. At the end of 2017, eBay marketplace had 170 million active registered users. In the second quarter of 2018, the online platform reached 175 million active users.

On eBay, any registered member has the possibility to list a product. When listing a product, the seller must describe the items and their policies such as shipping cost, acceptable methods of payment, the number of days that the auction will be active and return policies. Once a seller lists an auction on eBay, it can be publicly visible and only registered eBay users can bid on the good. There are two ways of selling goods on eBay: fixed price listings and auction style listings. Fixed price listings are similar as in stock retail product; the buyer can make a purchase immediately. This kind of listing is easy to identify on eBay by clicking the Buy it Now button and pay the price listed next to the button. The second kind of listing has a Place Bid button. Auctions listed are English auction, in which the highest bid becomes the closing price of the auction. Sometimes bidders will be outbid as soon as they enter the bid, however the bid they entered was higher than the current bid indicated on the product listing. When this occurs, eBay will immediately notify the bidders and bidders will have a chance to bid again by increasing their bids. Such as Cabral and Hortacsu (2010) paper, our study will not describe in detail the price formation process on eBay.

To have a certain vision of eBays position, it is crucial to understand the specific nature of eBays business model. As mentioned earlier, eBays allows sellers to list their items and buyers to find the items they want. EBay is not a retailer; it acts as an intermediary between buyers and sellers. Therefore eBay does not hold or deliver items that are traded on its platform. The online website gets its revenue from seller fees acquired upon successfully finished auctions.

In order to allow reputation systems to control online transaction between buyers and sellers, eBay uses a rating system. After each transaction, buyers and sellers can rate each other by posting feedback. Buyers can post a positive, negative, or a neutral rating, as well as a comment. Over time, registered members of eBay establish a feedback profile, or reputation, based on the ratings left by others. Ratings are combined to create feedback scores calculated according to the following system: positive rating rise feedback score by 1 point, negative rating reduce feedback score by 1 point and neutral rating leave feedback score the same. In addition to leaving a general rating of positive, neutral or negative for a seller, buyers can also leave detailed seller ratings. Ratings can be more detailed in four areas: Item as described (level of accuracy of the item described), communication (whether seller responds to buyers questions in a professional manner), shipping time (rate the seller on the time it took to dispatch the good) and shipping charges (reasonable costs charges).

As a summary, each potential buyer willing to buy from a specific seller can capture the following publicly available information: 
1) Positive feedback percentage: is calculated based on the total number of positive and negative feedback ratings for transactions that ended in the last 12 months: Positives/(Positives + Negatives). Likewise, negative feedback percentage can be calculated in the same way: Negatives/(Positives + Negatives).

2) Number of items sold for each seller during his stay on eBay. this information could be difficult to capture on eBays seller profile.

3) Types of eBay sellers: based on how the seller is rated, three seller level could be assigned: Top rated and Power Sellers (regularly get highest customer's rating, ship items quickly, have earned a track record of excellent service), Above standard (meeting the eBay minimum requirements and looking well after customers) and Below standard (not meeting one or more of the minimum eBay standards for customer service quality).

4) Recent feedback ratings: shows the number of positive, negative and neutral overall feedback ratings the seller has received in the last month, last 6 months, and last 12 months.

5) Detailed sellers rating: as previously mentioned, detailed seller ratings can provide the buyer with a more complete record of a seller's performance. Detailed seller ratings systems are based on a 1 to 5 star scale. 5 stars is the highest rating, and 1 star is the lowest. Average detailed seller ratings are calculated on a rolling 12-month basis and will be published when at least 10 ratings have been posted. Potential buyers can use all the information left for of each seller to form expectations about the behavior of this specific seller in the future.

6) Comments left for others: list of textual comments left from a seller or a buyer, the date when the comment was left and the revised feedback (number of negative or neutral feedback buyers that have been revised for a specific seller).

7) Seller user ID history: contains the user ID that this seller has used on eBay, the day he registered on eBay and the end date.

On eBay, reputation can be counted in many possible ways. Reputation can be characterized by the number of positive, negative and neutral feedbacks a seller has got in previous auctions. Moreover, any function containing one or more of positive, negative and neutral number, can be considered as a reputation measure. Of all possible functions, the number of positive ratings, minus the number of negative ratings, as well as the percentage of positive or negative ratings appears interesting. Figure 1 shows an example of the form of a feedback profile for each seller registered on eBay.

\section{The Effect of Negative Feedback}

A noticeable remark concerning eBay feedback profile is that it is so positive (Resnick and Zeckhauser, 2002). Negative and neutral feedbacks are rare on eBay. This is consistent with Gurtler and Grund, (2006) [23] who also indicate that negative feedback should work as a strong stigma. Negative feedback has a much larger impact than positive feedback ratings (Lucking-Reiley et al., 2007). Thus, negative feedback received by a seller should be much more significant 


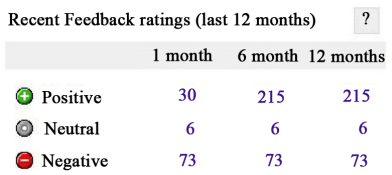

(a)

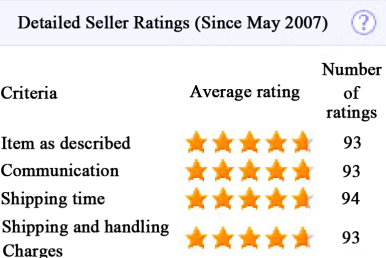

(b)

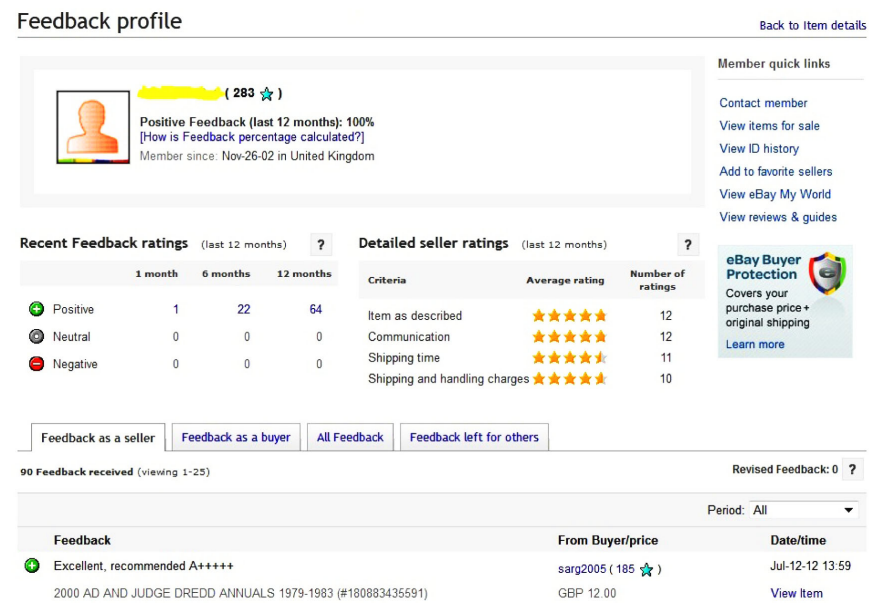

(c)

Figure 1. The form of a Feedback Profile for each user on eBay. (a) Recent feedback ratings; (b) Detailed seller ratings; (c) Feedback profile.

and more informative than positives in influencing a seller's reputation (Resnick and Zeckhauser 2002). In the same line of Resnick and Zeckhauser, the reputation measure used in this study is the number and the percentage of negative ratings.

Many factors can explain the reason why a seller may receive negative feedback. Negative rating can be a signal that the quality of the sellers products has decreased. Furthermore, negative feedback can produce changes in the performance of the seller and changes in the buyers behavior towards the seller.

With this perspective, sellers behavior can change and take the five following types:

Seller type 1: Seller can start with a positive reputation and survives on eBay without receiving any negative feedback.

Seller type 2: Seller can start with a positive reputation and from a certain period start receiving negative feedback [24]. Receiving a negative rating would make the seller more likely to receive another. If buyers expect than the seller will not do some effort to salvage his reputation, it seems rational for the buyers to not demand the item from this seller. That will decrease the demand for the 
sellers products, which leads the seller to exit the market.

Seller type 3: Seller can start with a negative reputation. Responding to that negatives, the seller tends to give high effort in the future and that by being more careful and conservative in describing the products, more responsive in the communication, quicker in shipping, and more careful in the packaging.

Seller type 4: Seller can start with a positive reputation, receive a single negative feedback and then salvage his reputation. In this case, seller will not be affected much by this negative feedback. A negative feedback may result from factors beyond the control of the seller.

Seller type 5: Seller can start with a negative reputation and is not willing to give high effort in the future to ameliorate his reputation. This type of seller offer lower quality service after getting a negative rating, which can be observable in the form of more negative rating on future transactions. Thus, as the seller keeps the same path, he may expect that one day he could be out of the market.

As it can be observed, negative rating reflects unfavorably on the seller. As previously mentioned, a negative rating may result from reasons beyond the control of the seller. In spite of that, natural Bayesian updating of beliefs will conduct customers to be more suspicious of a seller after getting a negative rating.

In response to negative feedback, buyers attitude towards the seller can take the two following forms:

Buyer type 1: facing a disreputable seller, the buyer may be willing to pardon a single bad behavior. If this occurs, the probability of negative rating should have no effect on the seller situation.

Buyer type 2: facing a disreputable seller, the buyer may not be willing to pardon a sequence of previous bad behavior. If this happens, the probability of negative rating should rise for transactions after the seller gets a negative rating.

\section{5. eBay Sellers' Type}

In order to reveal if those five types of sellers exist in the online market, particularly on eBay, observations from eBays website were gathered from January 2015 to January 2017. In total, 600 observations were collected over the period, observations generated on 25 sellers. To reduce the effect of item-level heterogeneity, our attention will be focused on a homogenous product. Hence Tennis racket product has been selected. The choice of Tennis racket was made for two main reasons. First, this type of item has a relatively high price, which leads the buyer to worry about the behavior of the seller with whom he will perform. Indeed, buyers place more importance on the feedback profile of sellers when the price of the item is high because they have more to lose if the seller has not been trustworthy in previous period. Secondly, in order to focus on each transaction made between seller and buyer, we have chosen an item that is not offered in large quantities on eBay.

Among the information selected, some are found in the seller's feedback pro- 
file and others are calculated. On the one hand, information that are easily found on the seller's page are the following: the percentage of positive feedback, the duration of registration (to see if the seller is still in the market or abandon the market), the type of seller, and the color of the stars representing the detailed feedback rating. On the other hand, the percentage of negative feedback and the percentage of neutral feedback were calculated manually. On eBay, completed sales include all items placed by a specific seller. These completed sales include successful sale (number of items that result in a sale) and unsuccessful sale (number of items that did not result in a sale), then the percentage of sale for each seller was calculated. Our data collection starts with 35 sellers offering Tennis racket, in the end of the period, only 25 sellers meet the requirements. The transaction progress path was tracked from the beginning till the end.

At a final stage the transaction level information collected for each transaction allow us to see:

1) The number of item for sale by a seller.

2) Among the item for sale the number of sold item.

3) The nature of the feedback left for each specific seller.

4) If the seller stays or exits the market.

The same collected method was used for each seller throughout the study period. At a final stage, we summed up for each seller the transaction information mentioned above. Results collected for the 25 sellers during the two years of this study implicate that on eBay, seller are affected by negative feedback received.

As presented above, five types of sellers are active on eBay. Figure 2 and Figure 3 clearly show these five types and the impact of seller reputation on the percentage of sale and on the item sale price, respectively, for each of these five types.

\section{Effects of seller feedback on sales}

In Figure 2, we can see that the percentage of sale is getting higher, as long as the seller is getting positive feedback. And once the seller gets his first negative feedback, the percentage of sale starts decreasing which leads some sellers to get out of the market.

\section{Effects of seller feedback on sale price}

Figure 3 shows that more the seller is having positive feedback, more he is capable of increasing the item sale price. And once the seller starts getting negative feedbacks, the item sale price drops to a lower level.

In addition to that, Table 1 exposes the impact factor calculated for each type of seller on each period. As it can be observed, impact factors for seller 2 and 5 are low. Indeed, these sellers run out of business.

\section{Construction and Analysis of Stochastic Model}

This study will focus on how negative feedback affects the behavior of the seller. To sum up, we are interested in the analysis of negative feedback effect on sellers. In the next section, we study Discrete Markov Chain Stochastic model representing this application. 


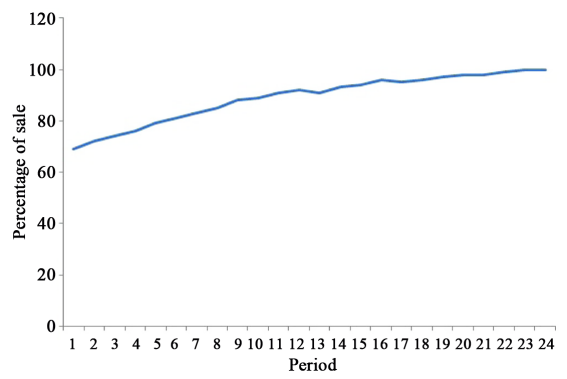

(a)

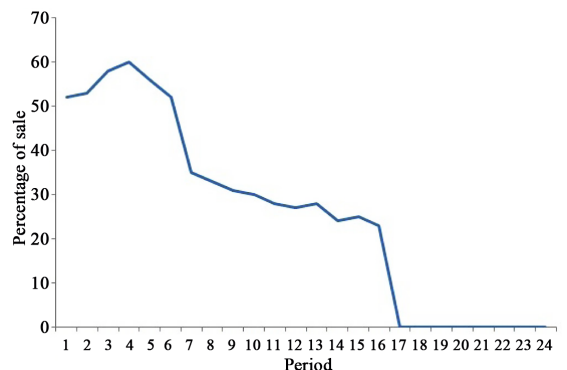

(b)

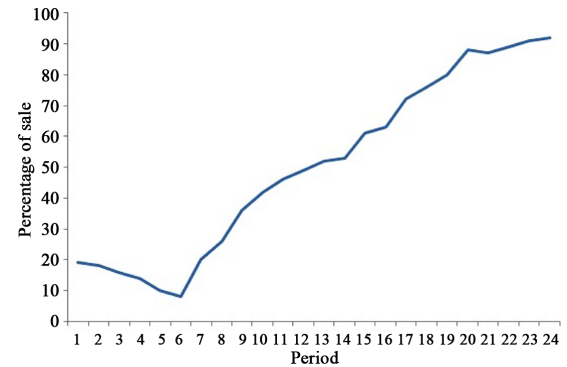

(c)

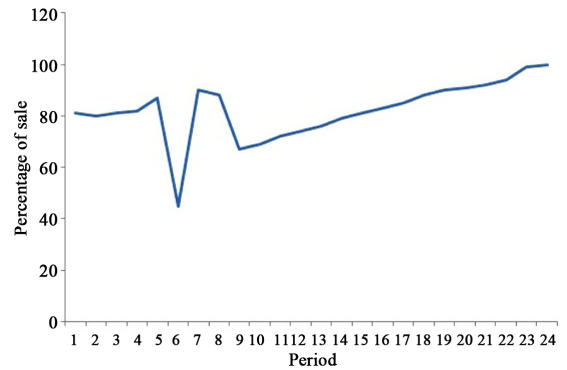

(d)

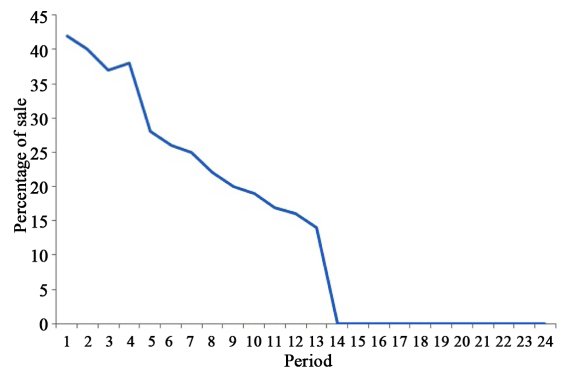

(e)

Figure 2. Impact of seller reputation on sale rates. (a) Seller type 1; (b) Seller type 2; (c) Seller type 3; (d) Seller type 4; (e) Seller type 5. 


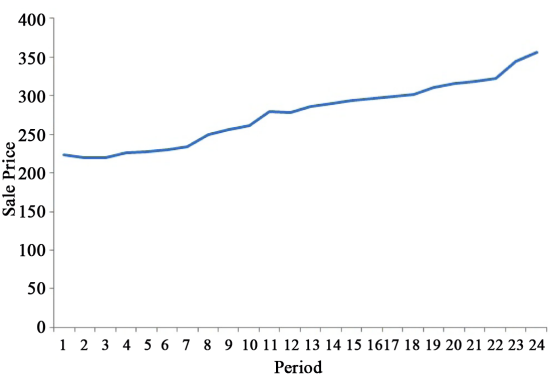

(a)

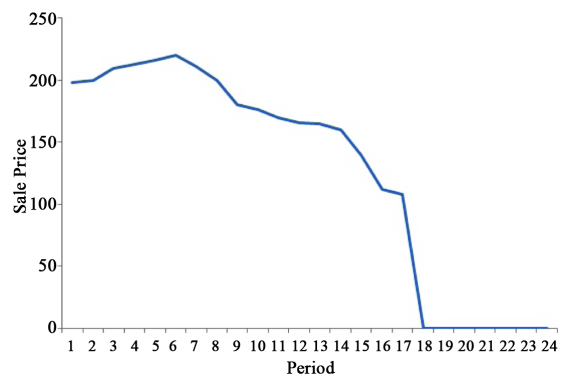

(b)

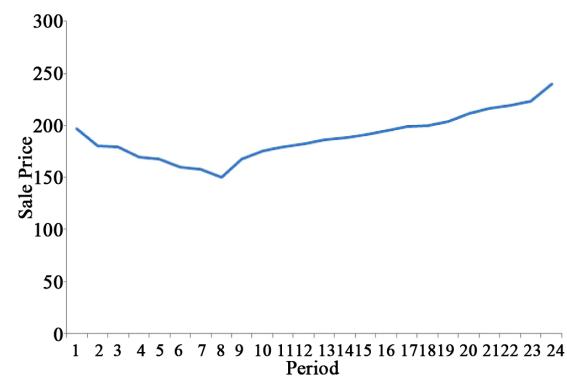

(c)

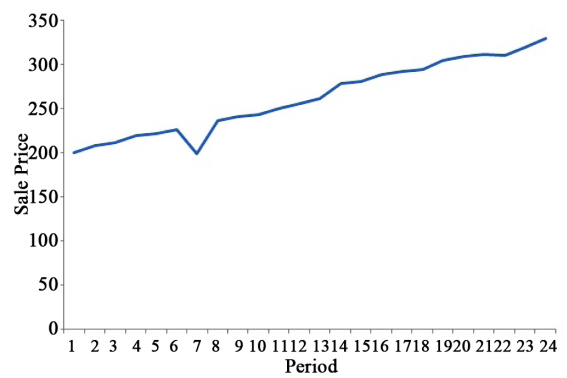

(d)

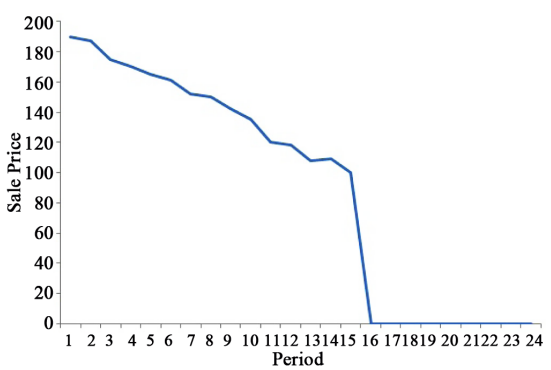

(e)

Figure 3. Impact of seller reputation on sale price. (a) Seller type 1; (b) Seller type 2; (c) Seller type 3; (d) Seller type 4; (e) Seller type 5. 
Using these symbols, our study will be elaborated by letting:

I: Item Price

$S$ : Number of items sold for specified sellers

$P$ : Number of positive feedback

$Q$ : Number of negative feedback

$p$ : Probability associated with positive feedback

$q$ : Probability associated with negative feedback

e: Probability associated with no feedback

Let

$$
p=\frac{P}{S}, q=\frac{Q}{S},
$$

and

$$
e=S-(P+Q) / S
$$

Thus, we propose $(p-q) \times I \times S /(1+S)$ as the impact factor on seller.

Buyers are not willing to buy from sellers that have more negative than positive feedback. In other word the impact factor becomes negative, sellers run out of business which is proven in our Table 1.

Suppose that, $\epsilon$ is a threshold representing the risk that a buyer is willing to take.

First case: When $(p-q) \times I \times S /(1+S) \ll \epsilon$ :

- If $S$ is very small $\Rightarrow(p-q)$ is disregarded.

- If $S$ is large and $(p-q)$ is small $\Rightarrow$ buyers are discouraged to buy.

Second case: When $(p-q) \times I \times S /(1+S) \gg \epsilon$ :

- If $S$ is large $\Rightarrow(p-q)$ is taken into consideration.

- If $S$ is large and $(p-q)$ is large $\Rightarrow$ the buyer will increase the purchase.

A stochastic model requires a state space and a transition matrix. In our application, both time and state space are discrete. Let $p_{j i}$ be the probability of transferring from state $i$ to state $j$. By referring to Figure 4, there is one absorbing state, which is the initial state 0 with $p_{00}=1$. Between each state there is a transition probability ( $p, q$ and $e$ ).

We define in the transition matrix of the buyer-seller negative feedback problem:

" $p$ " the probability of receiving positive rating.

" $q$ " the probability of receiving negative rating.

" $e$ " the probability of neutral rating.

Clearly $p+q+e=1$.

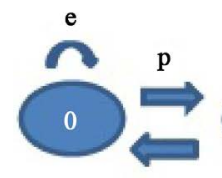

q
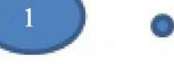

Figure 4. The directed graph considering positive feedback, negative feedback and no feedback. 
Table 1. Impact factor for each type of seller. (a) Seller type 1; (b) Seller type 2; (c) Seller type 3; (d) Seller type 4; (e) Seller type 5.

(a)

\begin{tabular}{|c|c|c|c|c|c|}
\hline Period & Price & Number of Items Sold & Positive Feedback & Negative Feedback & Impact Factor \\
\hline 1 & 223 & 50 & 50 & 0 & 218.627451 \\
\hline 2 & 220 & 56 & 56 & 0 & 216.1403509 \\
\hline 3 & 219 & 64 & 64 & 0 & 215.6307692 \\
\hline 4 & 226 & 61 & 61 & 0 & 222.3548387 \\
\hline 5 & 228 & 56 & 56 & 0 & 224 \\
\hline 6 & 230 & 59 & 59 & 0 & 226.1666667 \\
\hline 7 & 234 & 60 & 60 & 0 & 230.1639344 \\
\hline 8 & 250 & 68 & 68 & 0 & 246.3768116 \\
\hline 9 & 256 & 69 & 69 & 0 & 252.3428571 \\
\hline 10 & 261 & 76 & 76 & 0 & 257.6103896 \\
\hline 11 & 280 & 81 & 81 & 0 & 276.5853659 \\
\hline 12 & 278 & 88 & 88 & 0 & 274.8764045 \\
\hline 13 & 286 & 92 & 92 & 0 & 282.9247312 \\
\hline 14 & 290 & 99 & 99 & 0 & 287.1 \\
\hline 15 & 294 & 93 & 93 & 0 & 290.8723404 \\
\hline 16 & 296 & 97 & 97 & 0 & 292.9795918 \\
\hline 17 & 299 & 103 & 103 & 0 & 296.125 \\
\hline 18 & 302 & 105 & 105 & 0 & 299.1509434 \\
\hline 19 & 310 & 110 & 110 & 0 & 307.2072072 \\
\hline 20 & 316 & 119 & 119 & 0 & 313.3666667 \\
\hline 21 & 319 & 121 & 121 & 0 & 316.3852459 \\
\hline 22 & 323 & 122 & 122 & 0 & 320.3739837 \\
\hline 23 & 345 & 130 & 130 & 0 & 342.3664122 \\
\hline 24 & 356 & 135 & 135 & 0 & 353.3823529 \\
\hline
\end{tabular}

(b)

\begin{tabular}{cccccc}
\hline Period & Price & Number of Items Sold & Positive Feedback & Negative Feedback & Impact Factor \\
\hline 1 & 198 & 40 & 38 & 0 & 183.5121951 \\
2 & 200 & 50 & 48 & 1 & 184.3137255 \\
3 & 210 & 52 & 48 & 0 & 190.1886792 \\
4 & 213 & 50 & 47 & 0 & 196.2941176 \\
5 & 216 & 51 & 50 & 0 & 207.6923077 \\
6 & 220 & 53 & 48 & 4 & 179.2592593 \\
7 & 211 & 48 & 40 & 0 & 172.244898 \\
8 & 200 & 40 & 30 & 5 & 121.9512195 \\
9 & 180 & 40 & 26 & 9 & 74.63414634 \\
10 & 176 & 37 & 30 & 5 & 115.7894737 \\
11 & 170 & 30 & 26 & 2 & 131.6129032 \\
\hline
\end{tabular}


Y. M. Dib et al.

\section{Continued}

\begin{tabular}{cccccc}
\hline 12 & 166 & 30 & 25 & 2 & 123.1612903 \\
13 & 165 & 25 & 10 & 6 & 25.38461538 \\
14 & 160 & 20 & 7 & 6 & 7.619047619 \\
15 & 140 & 8 & 1 & 7 & -93.33333333 \\
16 & 112 & 2 & 0 & 2 & -74.66666667 \\
17 & 108 & 0 & 0 & 0 & 0 \\
18 & 0 & 0 & 0 & 0 & 0 \\
19 & 0 & 0 & 0 & 0 & 0 \\
20 & 0 & 0 & 0 & 0 & 0 \\
21 & 0 & 0 & 0 & 0 & 0 \\
22 & 0 & 0 & 0 & 0 & 0 \\
23 & 0 & 0 & 0 & 0 & 0 \\
24 & 0 & 0 & 0 & 0 & 0 \\
\hline
\end{tabular}

(c)

\begin{tabular}{|c|c|c|c|c|c|}
\hline Period & Price & Number of Items Sold & Positive Feedback & Negative Feedback & Impact Factor \\
\hline 1 & 197 & 28 & 20 & 2 & 122.2758621 \\
\hline 2 & 180 & 30 & 22 & 3 & 110.3225806 \\
\hline 3 & 179 & 22 & 16 & 4 & 93.39130435 \\
\hline 4 & 170 & 20 & 17 & 1 & 129.5238095 \\
\hline 5 & 168 & 20 & 15 & 2 & 104 \\
\hline 6 & 160 & 19 & 15 & 2 & 104 \\
\hline 7 & 158 & 21 & 17 & 4 & 93.36363636 \\
\hline 8 & 150 & 15 & 8 & 6 & 28.125 \\
\hline 9 & 168 & 15 & 8 & 5 & 31.5 \\
\hline 10 & 175 & 20 & 11 & 4 & 58.33333333 \\
\hline 11 & 179 & 25 & 18 & 0 & 123.9230769 \\
\hline 12 & 182 & 27 & 20 & 0 & 130 \\
\hline 13 & 186 & 29 & 24 & 0 & 148.8 \\
\hline 14 & 188 & 30 & 26 & 0 & 157.6774194 \\
\hline 15 & 191 & 35 & 30 & 0 & 159.1666667 \\
\hline 16 & 195 & 39 & 35 & 0 & 170.625 \\
\hline 17 & 199 & 40 & 37 & 0 & 179.5853659 \\
\hline 18 & 200 & 42 & 40 & 0 & 186.0465116 \\
\hline 19 & 204 & 46 & 44 & 0 & 190.9787234 \\
\hline 20 & 212 & 48 & 46 & 0 & 199.0204082 \\
\hline 21 & 216 & 50 & 50 & 0 & 211.7647059 \\
\hline 22 & 219 & 49 & 49 & 0 & 214.62 \\
\hline 23 & 223 & 54 & 53 & 0 & 214.8909091 \\
\hline 24 & 240 & 57 & 56 & 0 & 231.7241379 \\
\hline
\end{tabular}


(d)

\begin{tabular}{|c|c|c|c|c|c|}
\hline Period & Price & Number of Items Sold & Positive Feedback & Negative Feedback & Impact Factor \\
\hline 1 & 200 & 56 & 56 & 0 & 196.4912281 \\
\hline 2 & 208 & 49 & 49 & 0 & 203.84 \\
\hline 3 & 211 & 50 & 50 & 0 & 206.8627451 \\
\hline 4 & 220 & 53 & 53 & 0 & 215.9259259 \\
\hline 5 & 222 & 55 & 55 & 0 & 218.0357143 \\
\hline 6 & 226 & 50 & 48 & 1 & 208.2745098 \\
\hline 7 & 199 & 50 & 45 & 0 & 175.5882353 \\
\hline 8 & 236 & 58 & 58 & 0 & 232 \\
\hline 9 & 241 & 59 & 59 & 0 & 236.9833333 \\
\hline 10 & 243 & 60 & 60 & 0 & 239.0163934 \\
\hline 11 & 250 & 66 & 66 & 0 & 246.2686567 \\
\hline 12 & 256 & 69 & 69 & 0 & 252.3428571 \\
\hline 13 & 262 & 71 & 71 & 0 & 258.3611111 \\
\hline 14 & 279 & 72 & 72 & 0 & 275.1780822 \\
\hline 15 & 281 & 76 & 76 & 0 & 277.3506494 \\
\hline 16 & 289 & 78 & 78 & 0 & 285.3417722 \\
\hline 17 & 292 & 80 & 80 & 0 & 288.3950617 \\
\hline 18 & 295 & 86 & 86 & 0 & 291.6091954 \\
\hline 19 & 305 & 87 & 87 & 0 & 301.5340909 \\
\hline 20 & 309 & 91 & 91 & 0 & 305.6413043 \\
\hline 21 & 312 & 93 & 93 & 0 & 308.6808511 \\
\hline 22 & 311 & 89 & 89 & 0 & 307.5444444 \\
\hline 23 & 320 & 91 & 91 & 0 & 316.5217391 \\
\hline 24 & 330 & 96 & 96 & 0 & 326.5979381 \\
\hline
\end{tabular}

(e)

\begin{tabular}{cccccc}
\hline Period & Price & Number of Items Sold & Positive Feedback & Negative Feedback & Impact Factor \\
\hline 1 & 190 & 30 & 20 & 5 & 91.93548387 \\
2 & 187 & 29 & 19 & 10 & 56.1 \\
3 & 175 & 20 & 8 & 6 & 16.66666667 \\
4 & 170 & 19 & 8 & 10 & -17 \\
5 & 165 & 18 & 6 & 7 & -8.684210526 \\
6 & 161 & 20 & 8 & 5 & 23 \\
7 & 152 & 15 & 5 & 10 & -47.5 \\
8 & 150 & 9 & 1 & 8 & -105 \\
9 & 142 & 8 & 1 & 7 & -94.66666667 \\
10 & 135 & 6 & 1 & 5 & -77.14285714 \\
\hline
\end{tabular}




\begin{tabular}{cccccc}
\multicolumn{2}{c}{ Continued } & & & & \\
\hline 11 & 120 & 3 & 0 & 3 & -90 \\
12 & 118 & 1 & 0 & 1 & -59 \\
13 & 108 & 1 & 0 & 1 & -54 \\
14 & 109 & 0 & 0 & 0 & 0 \\
15 & 100 & 0 & 0 & 0 & 0 \\
16 & 0 & 0 & 0 & 0 & 0 \\
17 & 0 & 0 & 0 & 0 & 0 \\
18 & 0 & 0 & 0 & 0 & 0 \\
19 & 0 & 0 & 0 & 0 & 0 \\
20 & 0 & 0 & 0 & 0 & 0 \\
21 & 0 & 0 & 0 & 0 & 0 \\
22 & 0 & 0 & 0 & 0 & 0 \\
23 & 0 & 0 & 0 & 0 & 0 \\
24 & 0 & 0 & 0 & 0 & 0 \\
\hline
\end{tabular}

$$
p_{i j}=\operatorname{Prob} X_{n+1}=j / X_{n}=i \$= \begin{cases}p, & j=i+1 \\ q, & j=i-1 \\ e, & i=j\end{cases}
$$

with $X$ a variable in Stochastic process representing the number of item being sold.

$$
\left[\begin{array}{ccccc}
1 & q & 0 & \cdots & 0 \\
0 & e & q & \cdots & 0 \\
0 & p & e & \cdots & q \\
0 & 0 & \vdots & \ddots & \vdots \\
0 & 0 & 0 & \cdots & p
\end{array}\right]
$$

Let:

- $P_{00}=1$.

- there are two communication classes: $\{0\},\{1,2, \cdots\}$.

- The absorbing state: $\{0\}$.

It is clear that states 0 is absorbing. If we return to the transition matrix, we can notice that $p_{00}$ is equal to 1 because $p_{00}$ is the absorbing state. In addition to that, the initial conditions of the probability of absorption is: $A_{0}(t)=1$.

Let $a_{K}$ be the probability of absorption at $x=0$.

Let

$$
\sum_{n=0}^{\infty} a_{K n} \leq 1
$$

This leads to the second-order difference equation:

$$
a_{K}=p a_{K+1}+p a_{K-1}+e a_{K}
$$

Starting with selling $S$ commodity at time $t=0$, then 
- $a_{0 n}=1=\operatorname{prob}\left\{X_{n}=0 / X_{0}=0\right\}$

the probability of absorption at the $n$th time state is $a_{K n}$, with $a$ the probability of running out of business.

$a_{K n}$ had the following generating function.

- $A_{K}(t)=\sum_{n=0}^{\infty} a_{K n} t^{n}$

So

$$
A_{k}(t)
$$

is the generating function. Then

$$
a_{k}=A(1)=\sum_{n=0}^{\infty} a_{n}
$$

Let $\tau_{K}$ be the expected duration of the game. The expected duration of the game is the summation of the mean first passage times, $\mu_{0 K}$.

To get $\tau_{K}$ (expected duration of the game) by using the fact that

$$
\begin{gathered}
p+q+e=1 \\
\tau_{K}=p\left(1+\tau_{K+1}\right)+q\left(1+\tau_{K-1}\right)+e\left(1+\tau_{K}\right) \\
\Rightarrow p \tau_{K+1}+q \tau_{K}-(1-e) \tau_{K}=-1
\end{gathered}
$$

We first solve the homogeneous difference equation:

$$
p \tau_{K+1}+q \tau_{K}-(1-e) \tau_{K}=0
$$

We get:

- $\lambda_{1}=1$

- $\lambda_{2}=q / p$

Now we solve the none homogenous then we take:

- $\tau_{K}=L K$

- $\tau\{K+1\}=L\{K+1\}$

- $\tau\{K-1\}=L\{K-1\}$

$$
\Rightarrow \tau_{K}=C_{1}+C_{2}(q / p)^{K}+K /(q-p) .
$$

By using the boundary conditions $\tau_{0}=0=\tau_{N}$

We get:

$$
\tau_{K}=[1 /(q-p)]\left[K-N\left[\left(1-(q / p)^{K}\right) /\left(1-(q / p)^{N}\right)\right]\right] \text { with } p \neq q
$$

\section{Conclusions}

An essential challenge encountered by designers of online marketplaces is how to create enough trust to enable transactions between strangers. With online market, a buyer cannot directly examine the good before purchase and so must rely upon the exactitude and trustworthiness of the seller determining whether to buy. Apprehending this, designers of eBay built a rating system to evaluate the quality of the products described as well as their providers. Thus, the reputation can become a main factor in the buying decision. Buyer and seller performance change in response to changes in a seller's feedback profile. In this study, a buy- 
er-seller negative feedback problem is proposed. For the proposed problem, a Markov Chain is established. Five types of seller existing on the online market eBay were found. Particularly, effect of feedbacks on sellers who were running out of business is studied using discrete time process. Namely, seller type 2 and seller type 5 duration into business are established.

The findings of this study will redound to the benefit of each active user on eBay, considering that the reputation mechanism plays a crucial role in making the purchase from the good seller. The greater importance of the feedback left on the previous period after each transaction by buyers justifies the need for each seller to care more about his online behavior.

\section{Conflicts of Interest}

The authors declare no conflicts of interest regarding the publication of this paper.

\section{References}

[1] Kollock, P. (1999) The Production of Trust in Online Markets. JAI Press, Greenwich.

[2] Akerlof, A. (1970) The Market for "Lemons": Quality Uncertainty and the Market Mechanism. The Quarterly Journal of Economics, 84, 488-500. https://doi.org/10.2307/1879431

[3] Ba, S., et al. (1999) Building Trust in the Electronic Market Using an Economic Incentive Mechanism. Proceedings of the 1999 International Conference on Information Systems, Charlotte, 12-15 December 1999, 208-213.

[4] Ben-Ner, A. and Putterman, L. (2003) Trust in the New Economy. In: Jones, D.C., Ed., New Economy Handbook, Academic Press, San Diego.

[5] Resnick, P. and Zeckhauser, R. (2002) Trust among Strangers in Internet Transactions: Empirical Analysis of eBay's Reputation System. In: Baye, M., Ed., The Economics of the Internet and E-Commerce, Advances in Applied Microeconomics, Vol. 11, Emerald Group Publishing Limited, Bingley, 127-157.

[6] Bolton, G., et al. (2003) How Effective Are Electronic Reputation Mechanisms? An Experimental Investigation. Management Science, 50, 1463-1613.

[7] Dewan, S. and Hsu, V. (2004) Adverse Selection in Electronic Markets: Evidence from Online Stamp Auctions. Journal of Industrial Economics, 52, 497-516. https://doi.org/10.1111/j.0022-1821.2004.00237.x

[8] Eaton, D. (2002) Valuing Information: Evidence from Guitar Auctions on eBay. Murray State University, Murray.

[9] Houser, D. and Wooders, J. (2005) Reputation in Auctions: Theory, and Evidence from eBay. Journal of Economics and Management Strategy, 15, 353-369. https://doi.org/10.1111/j.1530-9134.2006.00103.x

[10] Livingston, J. (2005) How Valuable Is a Good Reputation? A Sample Selection Model of Internet Auctions. University of Maryland, College Park. https://doi.org/10.1162/0034653054638391

[11] Lucking-Reiley, D., et al. (2007) Pennies from eBay: The Determinants of Price in Online Auctions. Vanderbilt University Department of Economics, Nashville. https://doi.org/10.1111/j.1467-6451.2007.00309.x 
[12] McDonald, C., et al. (2002) Reputation in an Internet Auction Market. Economic Inquiry, 40, 633-650. https://doi.org/10.1093/ei/40.4.633

[13] Melnik, M. and Alm, J. (2002) Reputation, Information Signals, and Willingness to Pay for Heterogeneous Goods in Online Auctions. https://doi.org/10.2139/ssrn.452820

[14] Cabral, L. and Hortacsu, A. (2010) The Dynamics of Seller Reputation: Theory and Evidence from eBay. The Journal of Industrial Economics, 58, 54-78. https://doi.org/10.1111/j.1467-6451.2010.00405.x

[15] Klein, B. and Leffler, K. (1981) The Role of Market Forces in Assuring Contractual Performance. Journal of Political Economy, 89, 615-641. https://doi.org/10.1086/260996

[16] Shapiro, C. (1983) Consumer Information, Product Quality and Seller Reputation. The Bell Journal of Economics, 13, 20-35. https://doi.org/10.2307/3003427

[17] Allen, F. (1984) Reputation and Product Quality. The Rand Journal of Economics, 15, 311-327. https://doi.org/10.2307/2555440

[18] Resnick, P., et al. (2006) The Value of Reputation on eBay: A Controlled Experiment. Experimental Economics, 9, 79-101. https://doi.org/10.1007/s10683-006-4309-2

[19] Ba, S. and Pavlou, P. (2002) Evidence of the Effect of Trust Building Technology in Electronic Markets: Price Premiums and Buyer Behavior. MIS Quarterly, 26, 243-268. https://doi.org/10.2307/4132332

[20] Depken, C. and Gregorius, B. (2010) Auction Characteristics, Seller Reputation, and Closing Prices: Evidence from eBay Sales of the iPhone. International Journal of Electronic Business, 8, 170-186.

[21] Mickey, R. (2010) The Impact of a Seller's eBay Reputation on Price. The American Economist, 55, 162-169. https://doi.org/10.1177/056943451005500217

[22] Canals-Cerda, J. (2012) The Value of a Good Reputation Online: An Application to Art Auctions. Journal of Cultural Economics, 36, 67-85.

[23] Gurtler, O. and Grund, C. (2006) The Effect of Reputation on Selling Prices in Auctions. Discussion Paper Series of Governance and the Efficiency of Economic Systems.

[24] Dib, Y., et al. (2018) Optimization of Cash Management Fluctuation through Stochastic Processes. Journal of Mathematical Finance, 8, 408-425.

https://doi.org/10.4236/jmf.2018.82026 